\title{
Motor Insurance in the United Kingdom : A Description and an Appraisal*
}

\author{
by G. B. Hey and John D. Hey**
}

\section{Introduction}

The purpose of this paper is to describe and appraise the main features of motor insurance in the United Kingdom as viewed from the mid-1980s, and to compare the U.K. situation with that prevailing in other countries. In carrying out this description and appraisal, we shall attempt to alter the perspective through which motor insurance is normally analysed. Much of the literature (and indeed the first draft of this paper) views motor insurance through the eyes of the insurance companies; we shall try to redress the balance by wearing the spectacles of (actual and potential) policyholders. This sheds new light on existing practices in motor insurance in the U.K. and elsewhere.

The paper is organised as follows. Sections 2 to 7 inclusive contain an essentially factual (though inevitably comparative) brief description of motor insurance in the U.K. in the mid-1980s. Section 2 describes the market. Sections 3 and 4 describe the tariff structure: section 3 dealing with ex ante features and section 4 dealing with ex post features (that is, bonus/malus systems). These sections reveal that tariffing is complicated and highly "competitive" in the U.K. (particularly as compared with other European countries where strict regulation is enforced), so market information is clearly of crucial importance; section 5 deals with this. The descriptive sections conclude with sections 6 and 7 which deal, respectively, with legislation and supervision. Finally, section 8 provides a commentary and an appraisal.

* Presented at a Colloque International on Regulation et Tarification en Assurance Automobile at the Ecole polytechnique, Paris, June 1985. The first draft of the paper was written by the first-named author who is a Fellow of the Institute of Actuaries, recently retired as Motor Statistician of a large U.K. insurer. The second-named author, Professor of Economics and Statistics at the University of York, who had the pleasure of attending the colloquium, redrafted the paper in the light of the preoccupations of the participants at the colloquium. Between these two drafts, the paper has undergone a subtle metamorphosis, reflecting the different prejudices of the two authors.

** University of York, Department of Economics. 


\section{The market}

The U.K. motor insurance market, unlike that in many European countries, is largely unregulated. Companies do need to be authorized (by the Department of Trade and Industry (DTI), for each class of insurance business they conduct, and the DTI supervises the solvency of companies so authorized, as well as the "managers and controllers", but there is no direct state intervention in the companies' pricing (tariffing) policies.

The U.K. motor insurance market is also highly "competitive" in the sense that there is a very large number of companies supplying motor insurance (well over 100 in 1985), and no one company is dominant. The largest company (in terms of private motor insurance) accounts for some $9 \%$ of the market, the next for some $61 / 2 \%$; then there are 8 companies each of whom account for some $4 \%$ each, with a further 12 companies taking about $2 \%$ each (leaving a residual of a little under $30 \%$ for Lloyds and the remaining 100 -odd companies). To a certain extent there is some specialisation in certain areas of the market, but in most areas there is a high degree of competition. Many of the larger companies operating in the U.K. market also write a considerable volume of business abroad.

Over the past ten years there has been considerable stability in the U.K. motor insurance market. The last major disruption followed the demise of the Vehicle and General in 1971. Since then, the structure of the industry and the market shares of the various companies have remained roughly stable. In a sense, this is rather strange, given the considerable differences in premiums charged, which we now go on to describe.

\section{3. (Ex ante) Tarifis}

As compared with some European countries, U.K. insurance companies take a large number of factors into account when determining the ex ante premium for a particular risk. These factors are fairly uniform and are usually as follows :

(1) Rating area, that is the geographical location of the place where the vehicle is normally garaged.

(2) Rating group, that is the group (out of 7) into which the vehicle falls, based on size, value and power (and sometimes country of origin). The value is not usually taken further into account except for special vehicles which would be unusually expensive to repair (this may be achieved either by subdividing the highest group or by applying a loading).

(3) Age of vehicle. It is fairly common to allow a discount for the older vehicles, at least for comprehensive cover.

(4) Age of policyholder. There are loadings for age, maybe of over $100 \%$ for 17 -year-olds. The "normal" range tends to be for ages in 30 to 50 region, though there are often discounts for over 65 's.

(5) Class of use. Most individually-insured private cars are used for what is described as "social domestic and pleasure" use, but this is normally extended to cover business use provided the insured is in the vehicle when it is actually used for business purposes. Cover for occasional business use by, say, a spouse may be allowed by endorsement, often without additional premium. Farmers are usually allowed a discount of the order of $10 \%$, whilst use for commercial travelling may be loaded by up to 30 to $60 \%$. 
(6) Cover. There are four basic types of cover:

(i) Road Traffic Act (RTA), the minimum required by law in the place where the vehicle is used. This is most unusual in the U.K. except where cover is continued for a brief period after expiry of a period of insurance but the renewal premium has not been paid and the policy neither lapsed nor cancelled, or where the policy is extended to other parts of the EEC, in some cases.

(ii) Third Party (TP). This gives cover for bodily injury, to third parties, including passengers and for damage to property. It also gives cover to passengers for injuries and damage they themselves cause - for example, by opening a door carelessly.

(iii) Third Party Fire and Theft (TPFT). This is (ii) plus cover for damage by fire and theft of the vehicle and/or contents.

(iv) Comprehensive (Comp). This covers all the above heads of damage and, in addition, damage to the insured's own vehicle however caused.

In the U.K. it is thought that just over $70 \%$ of individual policies are for comp cover, about $20 \%$ for TPFT and just under $10 \%$ for TP.

(7) Voluntary excesses. A reduction of premium is given under comprehensive cover where the insured agrees to bear the first part of any claim for damage to his own vehicle. The range of discounts is from of $5 \%$ to $20 \%$ for excesses that are currently of the order $£ 30$ to $£ 200$. (Naturally these are increased from time to time to take account of the effects of inflation).

(8) Restricted driving. It is common to allow about $10 \%$ where driving is restricted to the insured and spouse.

(9) Garaging. In urban areas it is common to load by from 6 to $10 \%$ where the vehicle is normally kept in the street at night.

(10) Other. Further premium adjustments may be made for additional drivers, especially if they are young, for inexperienced insureds or drivers (maybe up to one year after passing the driving test) and for particularly bad past experience. It is rare for an insurer in the U.K. to refuse to offer cover, on the grounds that it is for the state not the industry to make driving legally impossible; but they may, and often do, load premiums heavily. A further premium is often payable to obtain a guarantee of protection for No Claims Discount. Some insurers allow limited "commuting" without additional premium.

With so many factors being taken into account, it is clear that premium calculations could be very complex. However, since nearly all the scales are multiplicative, some companies have introduced a points system whereby it is necessary only to add up the points for the appropriate level of each of the many factors and then look up the premium in a brief table. The system devised by the first-named author, and implemented by the Co-operative Insurance Society Ltd., fits comfortably on the face of a sheet $7 \times 4$ inches $(180 \times 100 \mathrm{~mm})$ on the back of which are the premiums for every point value and all 8 rates of (no claims) discount. The table stops at 44 points, currently corresponding to a gross premium of $£ 704.70$ at which level it is desirable for an underwriter to have a look at the facts. A recent copy of this table is reproduced as Figure 1 below. 
Figure 1

\begin{tabular}{|c|c|c|}
\hline \multirow{10}{*}{ 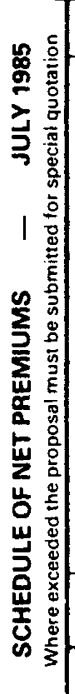 } & 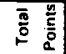 & 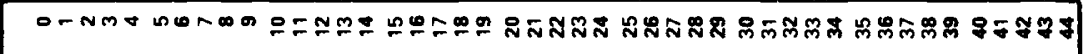 \\
\hline & & 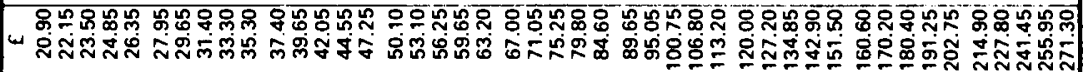 \\
\hline & : & 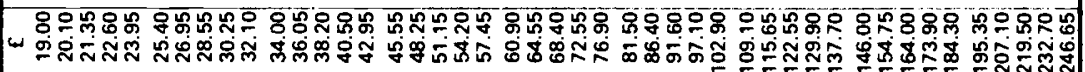 \\
\hline & ఫे & 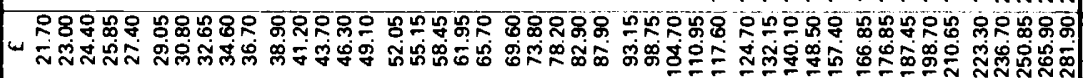 \\
\hline & : & 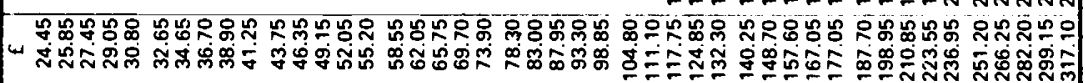 \\
\hline & לั & 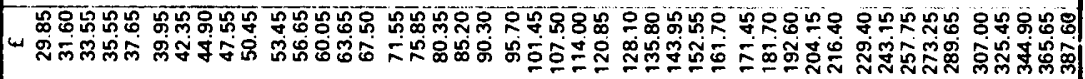 \\
\hline & 今ે & 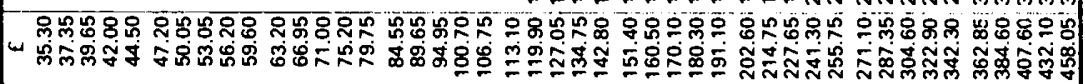 \\
\hline & ث્ & 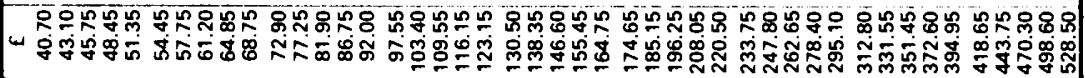 \\
\hline & 总咅 & 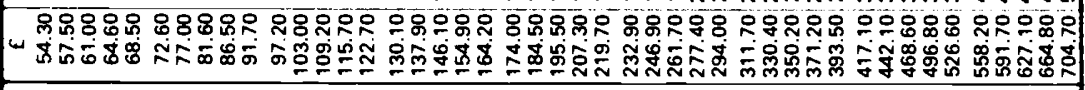 \\
\hline & & -DONNNN \\
\hline
\end{tabular}

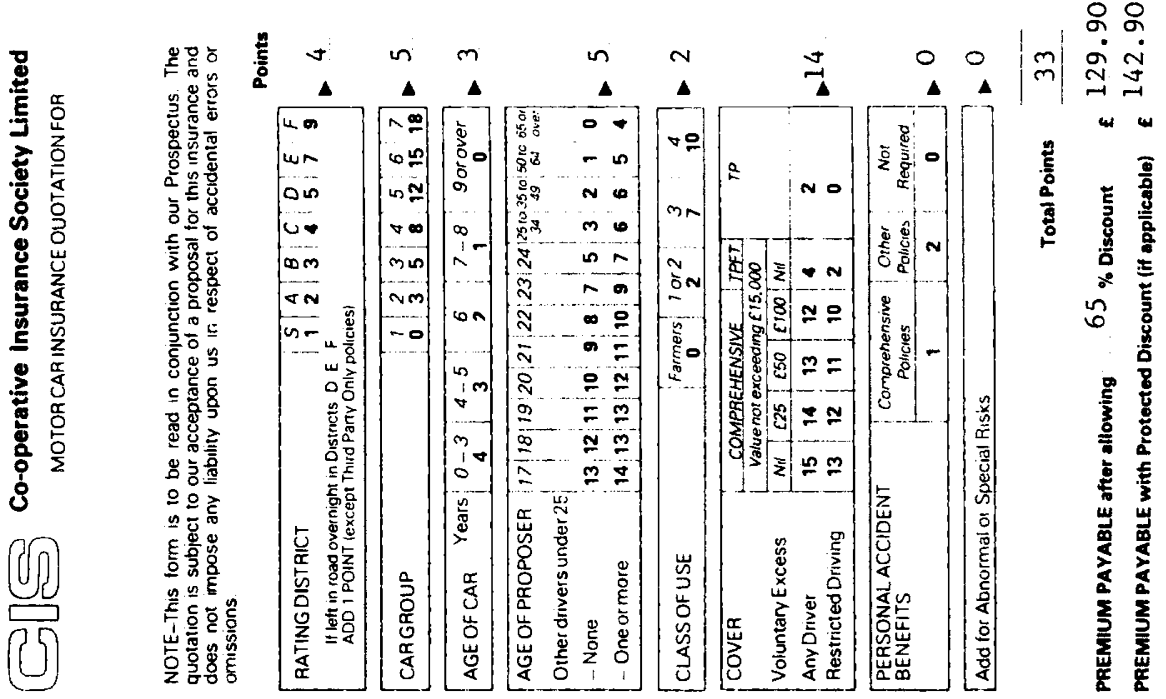


Whilst the structure, that is the set of factors taken into account, varies very little from one insurer to another, the weights given to the various factors by different companies tend to differ, often quite substantially. As a consequence, the premiums charged by different companies for apparently the same cover for ostensibly the same risk also vary substantially. Some illustrations are given in section 5 , when we shall comment on the implications.

\section{4. (Ex post) Tarifis}

Tariffs are varied ex post in the light of the policyholder's claims experience. For fleets of vehicles this is usually done through experience rating; for individually-insured vehicles, this is done through some form of no claim discount (or bonus/malus) scheme.

For fleets of vehicles, experience rating usually operates by taking the claims notified in the three years immediately prior to the next renewal date, and their likely cost, and using this total as a guide to calculating next year's premium. If the fleet is large enough, the average risk premium for the last three years, grossed up for expenses, commission, profit and contingencies, would determine the desired premium. For other, smaller, fleets a weighted average of this and the "book" rate will be used.

For individually-insured vehicles, some form of no claim discount scheme is almost always operated, though "guaranteed NCD" schemes are becoming increasingly common. (These, of course, imply that the premium depends on experience for an initial period, but once maximum discount is reached, future premiums are independent of experience subject usually to there being no more than, say, 2 or 3 claims in 5 years.) There is a bewildering variety of different NCD schemes in operation in the U.K. To give some idea of the complexity, we reproduce in Figure 2 a figure which was published in the December 1969 issue of Which? (a Consumer Association publication) in an article on car insurance. Since then the situation has probably become more complex.

It should be noted that many claims do not affect the discount for one reason or another. First, the policy will often provide that claims for windscreen breakage and any minor associated damage will not affect this discount. Second, where a claim is paid under "Knock-for-Knock"1 the discount will not be affected if the insured could have claimed his or her loss from the insurer of any other vehicle involved. Further, there are cases where it is found that there is no liability, or the incident has been notified under the terms of the policy (and recorded as a "claim" by the insurers) but the insured decides not to make a claim. With third party cover the percentage of claims that do not affect discount may be as high as 60 , whilst in comprehensive cover the percentage is around 50 .

For individuals who change insurance companies, it is normal for the "new" company to insert the individual into their no claim discount scheme at the same point as he would have been on if he had always been with that company. This practice gives some scope for dishonesty amongst individuals who have had an accident immediately after being issued

\footnotetext{
1 "Knock-for-Knock" is an agreement between two insurers. If two vehicles which they separately insure collide, each pays for the repair of its "own" vehicle, if it is insured comprehensively, irrespective of legal liability of either insurer or of the insureds. Most U.K. insurers have knock-for-knock agreements with most other U.K. insurers.
} 
Figure 2: Systems of No Claim Discounts
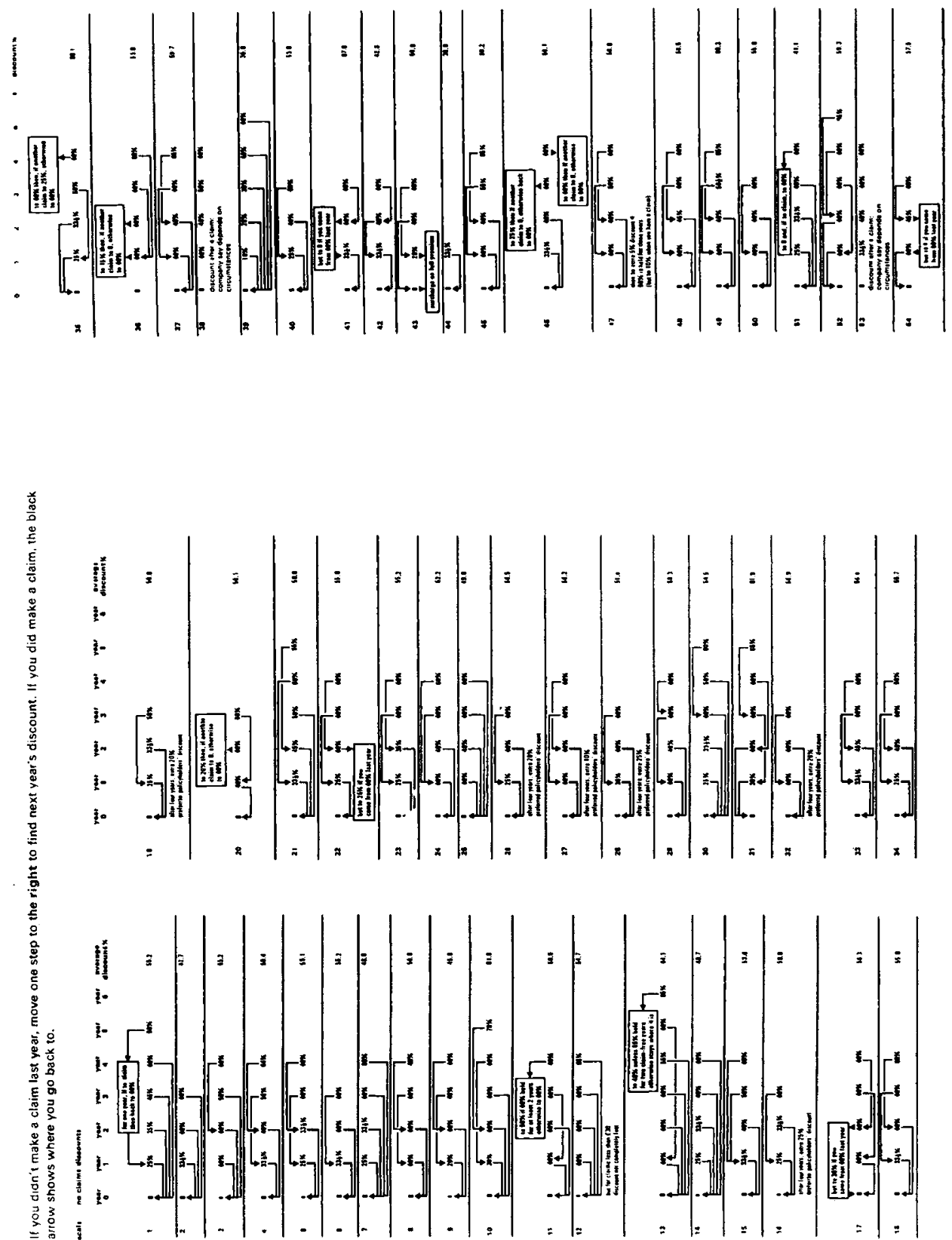
with a renewal notice (as the latter will be used as evidence of past experience by the "new" company). There is some evidence that some people fall prey to this temptation. (One study shows that insureds who had transferred from other insurers were significantly worse risks than those who had not transferred.)

It should be pointed out that, with the low claim frequencies currently experienced in the U.K., the frequency of "disallowed" claims (those which affect the entitlement to discount) is very low. For under-21's the average disallowed claim experience is about 1 in 5 years, whilst for the over 40's it falls to about 1 in every 15 years, or even lower. As a consequence, it is almost impossible for any NCD system to be efficient at distinguishing the good risk from the bad, or indeed at distinguishing the bad driver from the unlucky driver, or the good driver from the lucky driver. In fact, from the insurance companies' point of view, it adds very little to the information otherwise available (and already taken into account), and makes very little difference to the average percentage of basic premium paid over the lifetime of the insured.

(As an aside we should note that this comment relates specifically to the U.K., where, as we have already noted in section 3 , a wide range of factors is taken into account in determining the ex ante premium. These factors have been identified as statistically significant in analyses of past claim statistics. Together, they account for a sizeable proportion (about $50 \%$ ) of past claims experience. In other countries, where for a variety of reasons this is not the case, the position regarding the efficiency of NCD schemes is somewhat different. In general one might expect that the more factors identified ex ante the less efficient are NCD schemes, and vice versa. So, in those countries, where regulation, or inertia, or ignorance, reduce the extent of ex ante tariffing, the scope for NCD schemes to "rectify the situation" is that much larger. But this does not imply that NCD schemes are a good substitute - from either the insurer's or the insured's point of view - for an efficient ex ante tariffing procedure. We shall return to this point in section 8.)

\section{Market information}

It will have been realised by now that there are wide differences in the premiums charged by different companies (as a consequence of the differences in the loadings attached to the various factors in the ex ante tariffing) and there are similarly wide variations in NCD schemes. Therefore, the choice facing the individual policyholder is bewilderingly complex. Some idea of the scale of this complexity can be gleaned from Figures 3 and 4 which give a snapshot at one point in time. (Obviously this does not present a complete picture of the diversity, but it does give some flavour.) Each Figure reports premiums charged by different companies for apparently the same cover and ostensibly the same perceived risk: Figure 3 reports premiums for Third Party cover on a group 1,6-year-old car for a 36-yearold driver with maximum NCD; Figure 4 reports premiums for comprehensive cover (without excess) on a new and a six-year-old group 1 car driven by a 36-year-old driver with maximum NCD. Figure 3, for example, reveals a maximum premium $68 \%$ above the minimum with wide differences inbetween.

It should be noted that it is not the case that some companies are always persistently high and others persistently low. For example, the 5 maximum values in the analysis on the left-hand-side of Figure 4 involve 5 different companies; similarly the 5 maximum 


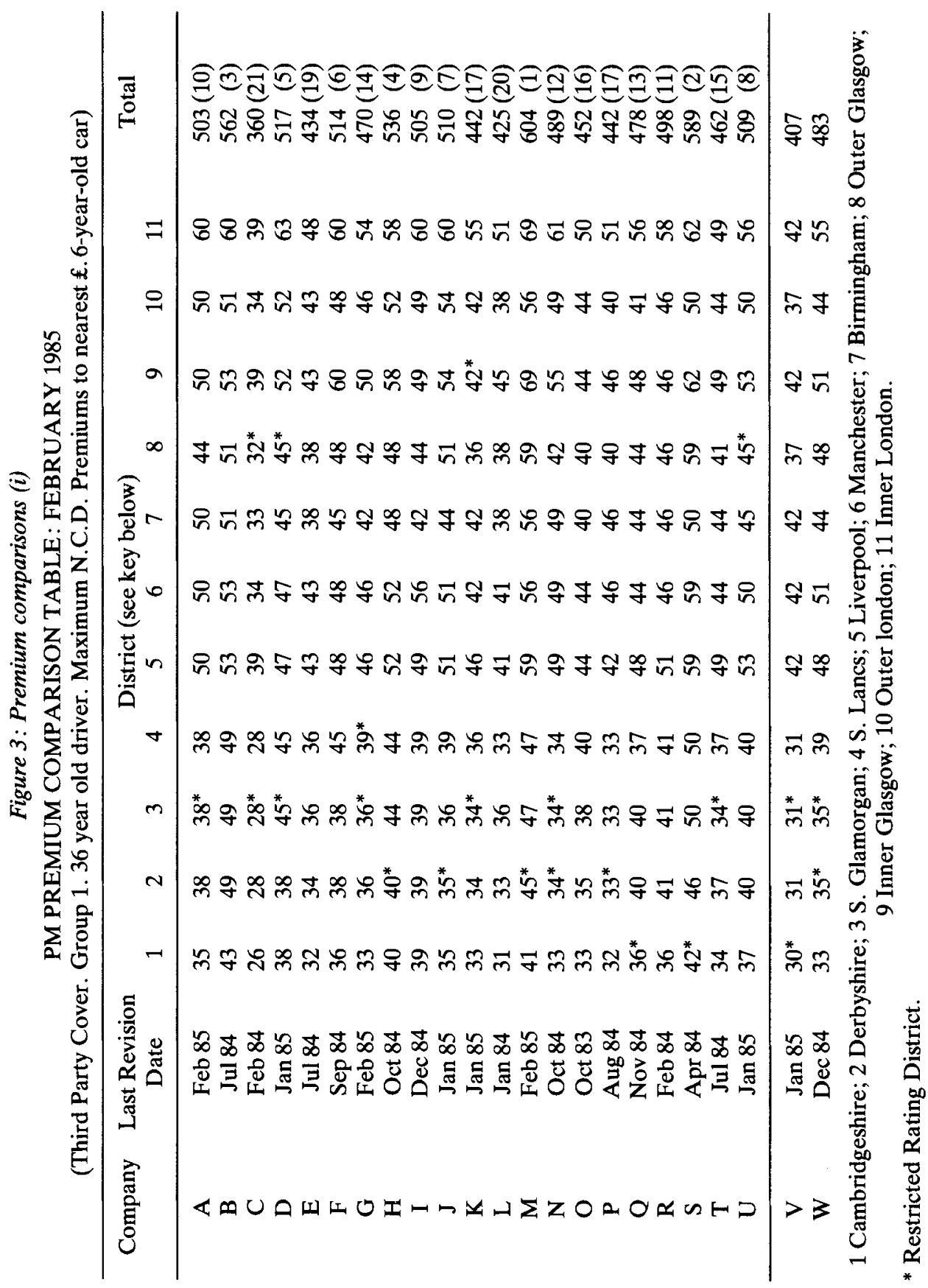




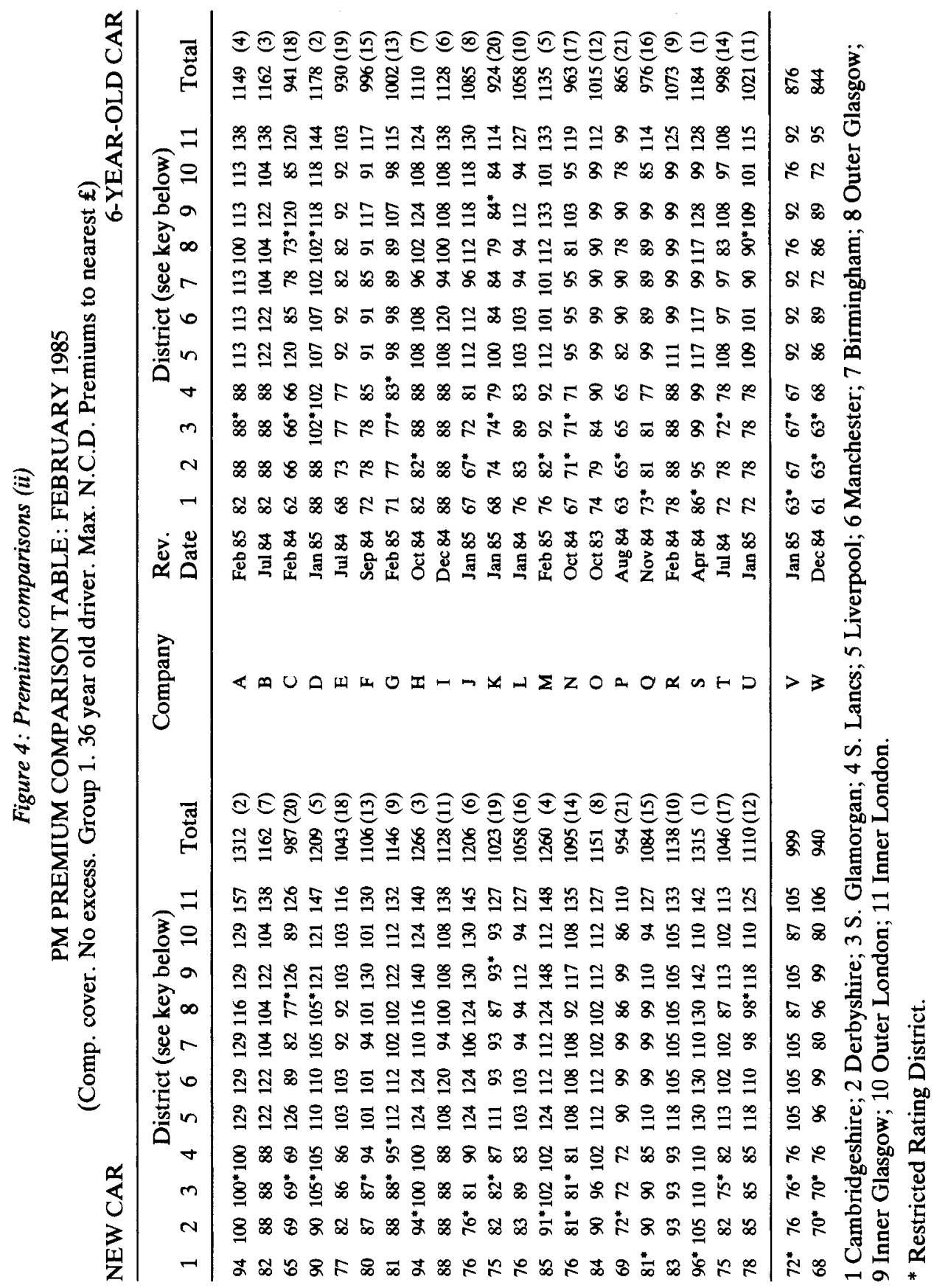


values in the analysis on the right-hand-side of Figure 4 involve 5 companies - but of which two are not represented in the top 5 on the left-hand-side. Moreover, in the top 5 in Figure 3 there are just 3 companies, of which 2 are in neither of the top 5's in Figure 4.

Nevertheless, there is clearly some systematic association between companies and premiums. Some companies tend to be generally more expensive than others. Part, but not all, of these differences can be explained in terms of differing quality of service (or differing perceived quality of service).

It is clear from the above that anyone wishing to find the lowest premium for his or her circumstances has to do a great deal of research. To some extent this should be the function of insurance brokers. It is increasingly being computerised, and several systems are now available to insurance brokers. (Since this paper was written a leading newspaper has obtained quotations for two risks from 3 such sources. The figures quoted are :

$\begin{array}{llccc} & \text { Source } & 1 & 2 & 3 \\ \text { Risk 1 } & \text { Minimum } & 186 & 184 & 161 \\ \text { Risk 1 } & \text { Maximum } & 460 & 274 & 522 \\ \text { Risk 2 } & \text { Minimum } & 378 & 378 & 319 \\ \text { Risk 2 } & \text { Maximum } & 756 & 860 & 964\end{array}$

Whilst we have some reservations about these figures and whilst they may apply to somewhat different covers, they do emphasise the difficulty in making decisions.)

Of course, some of the differences between the premiums charged by different companies for apparently the same cover and ostensibly the same risk can be explained, on closer inspection, in terms of differing qualities of service, and other intangibles. Some companies develop good reputations for settling claims rapidly and without quibble; others develop bad reputations. However, it is difficult for the newcomer to perceive these intangible differences, and the insurance broker may be reluctant to comment on them for fear of libel. There is also a fear amongst the insurance companies themselves that an increase in the amount of information available to policyholders might be counter-productive in the sense that the increased competition thereby generated might drive many insurance companies out of business.

\section{Legislation}

The general principle in the U.K. is that damages are payable only if there is negligence and the negligence is proved. It is also the case that if the injured party was partly to blame for his or her injury the damages should be reduced. There is no provision for a "contingency fee" system such as that operating in the U.S. If the defendant is found guilty he will normally be liable for the costs of both himself and the injured party, but if the injured party is partly to blame, the court has power to adjust the incidence of costs accordingly. The effect of this is that, if there is no negligence, there is no compensation, since there is no "no-fault" system operating. As a result if, say, a lorry driver has a heart attack and his lorry causes injury, there will be no claim against either him or the owner of the lorry. However, if there has been negligence, but the driver involved is uninsured or is not traced, or if, for any reason, his insurer does not pay (e.g. if it has gone into liquidation) the claim will be met by the Motor Insurers Bureau. This is a body which was set up in 1946 by the 
insurance industry and which is financed by a levy on all insurers conducting motor insurance in the U.K. Note, however, that it pays only for legal liability, which excludes property damage at the present time. It is assumed in a "hit and run" case that there was negligence.

It is also a principle of U.K. law that compensation must be by a lump sum; this covers "special damages" namely pecuniary loss up to the date of trial, as well as general damages (mostly for future loss of earnings, for dependency, or extra expenses for nursing). Finally, compensation is also payable for what is called "non-pecuniary loss", which is really for "pain and suffering" as distinct from purely financial loss. Some figures collected for the Pearson commission report (1978) suggested that about two-thirds of all damages were for non-pecuniary loss.

The difficulties in assessing lump sums have given rise to actuarial discussion but the courts in the U.K. have been most reluctant to accept actuarial advice. Even with such advice the result can be little better than a guess, since the needs of the victim depend, inter alia, on how long he will live, yet the courts, having considered his own circumstances, then assume that he will live for exactly the resulting "expectation of life". Since most people, and especially those who have been injured, do not live for even approximately their "expectation", it follows that some will get too much compensation, but others will run short of money when they are old and need it most. (Some of the difficulties may prove to have been eased by the introduction in July 1985 of the right of an injured person to return to the court for additional compensation if his or her condition worsens.) There is nothing in the U.K. comparable with the award of indexed annuities and, at least until very recently, insurers were most reluctant to issue annuities linked to a prices index, and even less willing to issue annuities linked to an earnings index. However, the recent issues of U.K. Government Index-linked stocks have been followed by the issue of some indexed annuities.

Whilst we have referred throughout to the courts, it should be noted that insurers and solicitors are well aware of the practices of the courts, so that only a small proportion of cases come to court; maybe they are as few as $1 \%$ of all damage claims. The Royal Commission under Lord Pearson which considered the provision of compensation for personal injury did envisage a limited amount of "no-fault" compensation. However, since it also made proposals for further damages where negligence could be proved it seems unlikely that this would make for much, if any, saving in costs and could well, because of this and other proposals, cause a large rise in costs both of compensation and in litigation. The proposals of the commission have not been put into practice (except for one glaring anomaly which they suggested should be abolished, and which was in fact abolished by the House of Lords on appeal).

\section{Supervision}

In the U.K., supervision of insurance operations is carried out by the Insurance Division of the Department of Trade and Industry (DTI). In the discussion below we shall confine attention to the supervision of insurance companies; the procedure as regards Lloyd's underwriters is rather different, but as it is of rather local interest, we shall not describe it.

The general principle of insurance supervision in the U.K. was for a long period that known as "freedom with publicity". By this was meant that insurers were required to publish, especially in life assurance, enough data to enable their accounts and returns to be 
verified by an informed outsider. This is all very well for life assurance, but it is far from adequate for general insurance. Under earlier Insurance Companies Acts companies were required to show in their accounts a level of solvency of a little over $10 \%$ of the written premium, net of reinsurances, for the year just ended. There was some control over the assets and the values placed on them but that is now of only historical interest.

Under the Insurance Companies Act 1982 the minimum required solvency margin is between $16 \%$ and $18 \%$ of the gross written premium (in accordance with EEC rules). There are provisions for reduction (up to $50 \%$ ) for reinsurance, and for increase if the claims basis applies, but this is common to all EEC insurers. However, whilst failure to maintain the new limits gives the DTI power to intervene and call for a scheme to restore the minimum margin, winding-up is not called for until the minimum guarantee fund of one-third of the above figures is reached.

The 1982 Regulations, and others, made under the 1982 Act specify in some detail the maximum amounts for many categories of investment and provide for valuation at market value.

There are two major problems in regard to the statistics which the DTI collects for which no solutions can be seen. The first is that, in the case of the U.K., and probably to a very much greater extent than in any other country, a large proportion of general insurance business is written abroad: some U.K. insurers do more business outside the U.K. than within and very often they conduct it through subsidiary companies, which do not make returns to the DTI. As a result their returns cover less than $50 \%$ of their world-wide business.

The other problem is that solvency is measured at market value. Now it so happened that U.K. insurers had such strong solvency margins that all - or at least all the large ones were able to show more than the minimum levels even at the end of 1974 when equity market prices had fallen by up to $70 \%$ in a short period. Had the margins been lower and many of the insurers been technically insolvent it is unthinkable that they would all have been stopped from trading; the rules would just have had to be altered!

Fixed minimum solvency margins irrespective of the mix of business, combined with the current state of the stock market, seem inappropriate to an intelligent supervision of insurers. But it is not easy to see what to put in its place.

The Policyholders Protection Act (1975) protects personal policyholders, through the Policyholders Protection Board, against the default of an authorized company by an ex post levy on surviving companies. This seems a strange procedure, particularly in insurance!

\section{Appraisal}

There are two rather strange features of the U.K. motor insurance market which appear to require further investigation. The first relates to the continued existence and operation of NCD schemes in the U.K. despite the relatively sophisticated system of ex ante tariffing. The second relates to the continuing large differences in ex ante tariffs for ostensibly the same risk despite the apparently high level of competition, and low level of supervision, in the U.K. market. We examine these in turn. 
Individuals take out insurance (over and above the minimum required by law) because they are risk-averse. They prefer to forfeit a fixed amount annually instead of experiencing varying losses from year to year, even though the fixed amount exceeds the expected value of the varying amount. This, of course, represents the profits and expenses of the insurance company. It therefore follows that policyholders do not like no claims discount schemes (as compared with flat-rate schemes with the same expected premium) since such schemes do not eliminate all the risk. (Unless, perhaps, if people get utility from being in the top discount category, per se.)

Insurance companies ostensibly like no claims discount schemes because they enable the companies to adjust the premium charged ex post - presumably towards the "correct" premium. But if the "correct" premium can be identified $e x$ ante then no such ex post adjustment is needed. Clearly there is a trade-off here, as we have already noted in section 4: the more closely one can identify the correct premiums ex ante, the less need there is for ex post adjustment through NCD schemes. (In any case, such schemes could be manifestly unfair, particularly in the context of the low claim rates currently experienced in the U.K. And NCD schemes seem an inappropriate way to tackle the moral hazard problem. See Bennett (1974) and Hey (1985) for more details.)

The large number of factors taken into account in ex ante tariffing in the U.K. essentially means that the range of uncertainty experienced by the insurance company concerning any particular individual's risk category is small. The scope for reducing it still further through NCD schemes is thus very restricted. We would therefore argue for the abolition of such schemes in the U.K. However, this argument does not apply to those European countries who are either very heavily regulated or take very few factors into account when fixing the ex ante tariff. Clearly there is scope in these countries for adjusting the tariff $e x$ post through the use of NCD schemes. Nevertheless, it is still undeniably better (for both company and policyholder) to improve the efficiency of the ex ante tariffing: the greater the reduction in uncertainty the greater will be the demand for insurance by risk-averse individuals.

(Of course, those individuals who are mis-classified by the ex ante tariff have a different view on such matters from those individuals who are correctly classified. But note rather interestingly, that an NCD scheme that is expressed in percentages (of basic premium) can never correct for an ex ante mis-classification.)

The second rather strange feature of the U.K. motor insurance market is the continuing large differences in ex ante tariffs for ostensibly the same risk. Some of these differences can clearly be explained in terms of factors identified by some companies and not by others, and in terms of intangible factors. Superior service, reputation and "brand loyalty" also play an important role (particularly amongst the elderly policyholders). Inertia is possibly also important. Nevertheless, some residual dispersion must still be left even after all these factors have been taken into account. Presumably this must be put down to ignorance amongst policyholders (or, at least, ignorance that is too expensive for individuals to reduce).

So we have a strange situation in U.K. motor insurance : in an industry whose very raison d'être is the elimination of risk we see the introduction of risk through no claims discount schemes and the introduction of risk through lack of information. 
In economics, there is a theory which states, in essence, that the effects of competition can be offset through "noisy" information (see, for example, Salop and Stiglitz [1977]). Is this what is happening in the U.K. motor insurance market?!

\section{REFERENCES}

BENNETT, M.C. (1974), "Why N.C.D ?", Journal of the Institute of Actuaries Students Society, $21,87-110$.

CONSUMERS ASSOCIATION (1979), “Car Insurance”, Which?, 157-177.

HEY, J.D. (1985), "No Claims Bonus", The Geneva Papers on Risk and Insurance, 10, 209-228

PEARSON (1978), Report of the Royal Commission on Civil Liability and Compensation for Personal Injury, HMSO.

SALOP, S. and STIGLITZ, J. (1977), "Bargains and Ripoffs: A Model of Monopolistically Competitive Price Dispersion", Review of Economic Studies, 44, 493-510. 